\title{
The QUinapril Ischemic Event Trial (QUIET) Design and Methods: Evaluation of Chronic ACE Inhibitor Therapy After Coronary Artery Intervention
}

\author{
Michele Texter, ${ }^{1}$ Robert S. Lees, ${ }^{2}$ Bertram \\ Pitt, ${ }^{3}$ Robert E. Dinsmore, ${ }^{2}$ and Andrew C.G. \\ Uprichard ${ }^{1}$ \\ ${ }^{\prime}$ Cardiovascular Clinical Development, Parke-Davis Pharmaceutical \\ Research, Division of Warner-Lambert Company \\ ${ }^{2}$ Boston Heart Foundation, Cambridge, Massachusetts \\ ${ }^{3}$ Department of Cardiology, University of Michigan, Ann Arbor. \\ Michigan
}

\begin{abstract}
Summary. The rationale, trial design, and statistical aspects of QUIET, the QUinapril Ischemic Event Trial, are described. QUIET is a prospective, double-blind placebocontrolled study that will assess the ability of the angiotensin-converting enzyme (ACE) inhibitor quinapril to reduce the rate of cardiac ischemic events and to slow or prevent the development of coronary artery atherosclerosis as assessed by serial angiography in a normolipidemic population without left ventricular dysfunction. The study began in September 1991 and has completed recruitment with 1740 patients across 38 centers ( 28 U.S., 4 Canada, 6 Europe) by the end of 1992. Patients are randomized to $20 \mathrm{mg}$ of quinapril or placebo once daily and continue in the study for 3 years. Study completion is projected for 1995 .
\end{abstract}

Cardiovasc Drugs Ther 1993;7:273-282

Key Words. clinical trials, coronary disease, angiotensinconverting enzyme inhibitors, atherosclerosis, drug therapy, ischemia, quinapril

In the search for the causes and cures for coronary artery disease, studies of interventions such as diet [1], drug therapy [2-4], and surgery [5,6] have reported promising trends in hyperlipidemic populations based on assessments of plasma lipid and lipoprotein changes, and angiographic evidence of lesion regression or lack of progression. However, because not all patients with coronary artery disease have abnormal lipid values, investigations are under way to delineate other pathophysiological mechanisms and treatment approaches.

In particular, in populations with confirmed coronary artery disease but without the primary diagnosis of hyperlipidemia, the calcium channel antagonists nifedipine and nicardipine have been shown to inhibit new lesion progression, albeit with adverse trends in clinical sequelae $[7,8]$.
Preclinical work with angiotensin-converting enzyme (ACE) inhibitors has prompted interest in the possible effects on coronary artery disease progression. Through a summation of angiotensin-blocking and bradykinin-potentiating effects, these drugs are thought to preserve endothelial integrity and to prevent lipid accumulation as well as to inhibit cellular growth and proliferation of the intimal lining. Other potential beneficial actions of ACE inhibitors include the antagonism of macrophage function [9] and migration $[10,11]$, and inhibition of sympathetic nervous system activity [12]. In preclinical studies, various ACE inhibitors reduced neointimal thickening in response to intimal injury of the rat carotid [13] and prevented atherosclerotic progression in both the rabbit [10] and monkey [14].

Among clinical investigations of $\mathrm{ACE}$ inhibitors as antiatherosclerotic agents to date is the Multicenter European Research Trial With Cilazapril Aiter Angioplasty to Prevent Transluminal Coronary Obstruction and Restenosis (MERCATOR) [15]. In this study the ACE inhibitor cilazapril had no effect on restenosis as assessed by angiography, but in the active treatment group the data did show an apparent trend toward fewer clinical cardiac endpoints, such as death, myocardial infarction, and coronary revascularization (Figure 1) [16].

A lower incidence of cardiovascular endpoints was also apparent with enalapril in the Studies of Left

Address for correspondence: Andrew C.G. Uprichard, MD, MRCP, Parke-Davis Pharmaceutical Research, Division of Warner-Lambert Company, 2800 Plymouth Road, Ann Arbor, MI 48105.

Received 18 September 1992; accepted \& December 1992 


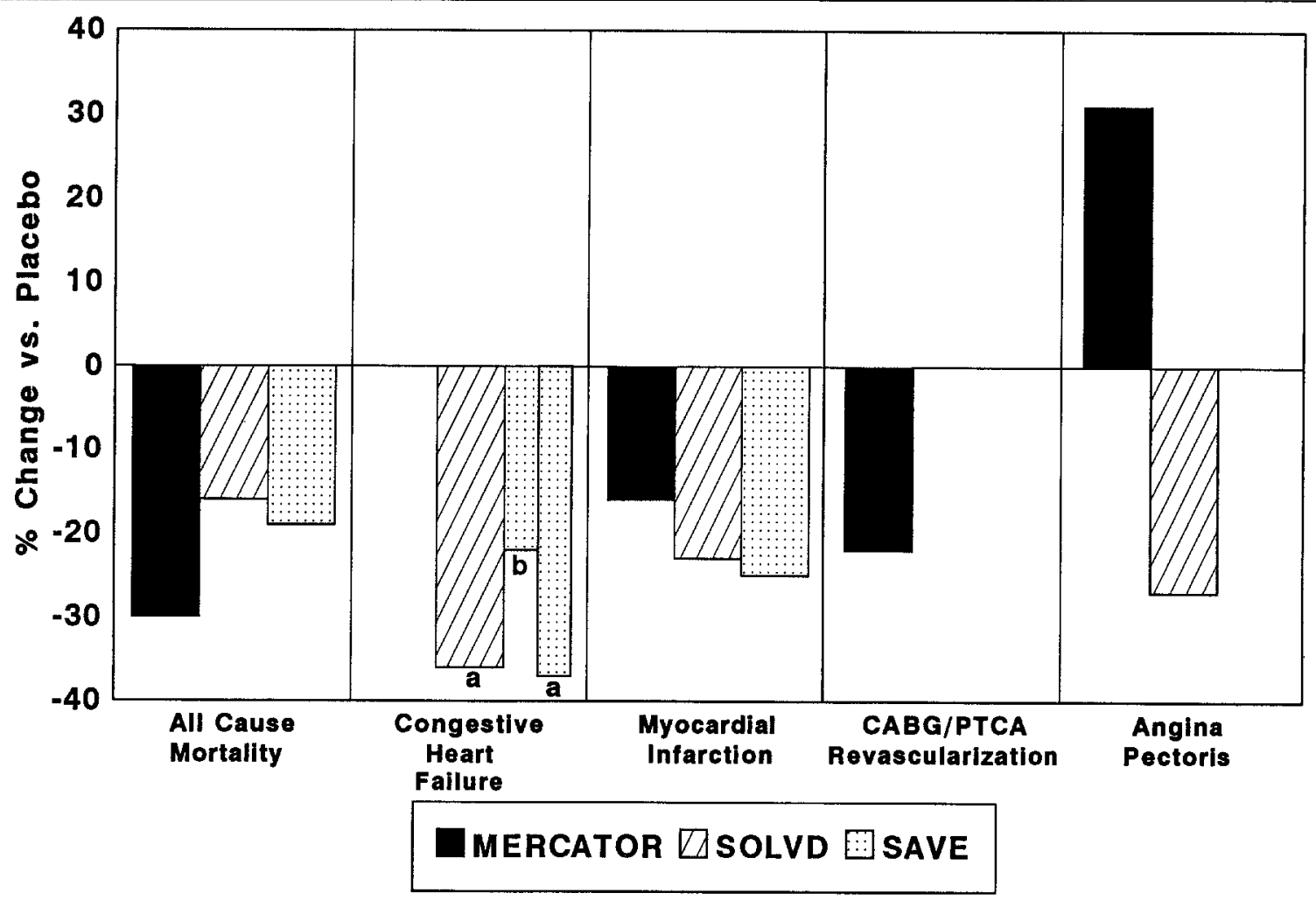

a Hospitalization for CHF
b Development of CHF

Fig. 1. Percent reduction in ischemic events vs. placebo for MERCATOR [16], SOLVD [17,18], and SAVE [19]. Mean treatment times: SOLVD, 41.4 months; MERCATOR, 12 months; SAVE, 7 months.

Ventricular Dysfunction (SOLVD) [17,18] and captopril in the recent postmyocardial infarction trial, SAVE [19] (Figure 1). Like MERCATOR, however, these antiischemic effects were observational findings and, until now, have not been the subject of formal hypothesis testing.

The QUinapril Ischemic Event Trial (QUIET), therefore, is the first study to investigate the longterm effects of ACE inhibition in a large, homogeneous population with normal low-density lipoprotein (LDL) cholesterol and left ventricular function, but with documented coronary artery disease requiring intervention in the form of angioplasty or atherectomy. In light of recent data supporting the existence of an autocrine-paracrine (tissue) renin angiotensin system subserving largely chronic adaptive cardiovascular changes [20], the ACE inhibitor quinapril was selected based on its documented potent binding to the converting enzyme in both arterial and cardiac tissue $[21,22]$. This prospective, double-blind, placebo-controlled trial will evaluate the ability of quinapril to reduce the rate of cardiac ischemic events and to slow or prevent the development of coronary artery atherosclerosis as assessed by serial angiography.

\section{Trial Design}

\section{Patient population}

QUIET is a double-blind, randomized, parallel-group, placebo-controlled study of 1700 men and women, 75 years of age or less, who have undergone successful single- or double-vessel angioplasty or atherectomy (Simpson device or excimer laser) within 72 hours prior to randomization. For purposes of this study, successful angioplasty is defined as a $>20 \%$ change in luminal diameter narrowing and a residual diameter of $\leq 50 \%$ stenosis in a patient without associated myocardial infarction or the need for acute coronary artery bypass grafting (CABG). Patients must also have at least one main coronary artery that has never been subjected to invasive intervention.

Patients are required to have LDL cholesterol levels $\leq 4.27 \mathrm{mmol} / \mathrm{l}(165 \mathrm{mg} / \mathrm{dl})$ without lipid regulating drugs and to be normotensive [systolic blood pressure (SBP) between 100 and $160 \mathrm{mmHg}$; diastolic blood pressure (DBP) $\leq 95 \mathrm{mmHg}$ ] at baseline. Patients with controlled hypertension may enter providing they are not receiving excluded antihypertensive medications. The left ventricular ejection fractions 
must be $\geq 40 \%$ by multiple-gated angiography (MUGA), echocardiography, or ventriculography at the time of initial angiography.

Not eligible for the study are patients who undergo any other intervention at the time of angioplasty or atherectomy, those with prior CABG, any other intervention within the 3 months preceding randomization, or myocardial infarction within the previous 7 days.

Excluded medications at the time of randomization include lipid-lowering agents and ACE inhibitors. After randomization, calcium channel antagonists are also excluded. Patients may not have other diseases, including Type I diabetes mellitus, renal disease, liver disease, or hepatic dysfunction by standard laboratory screen; or laboratory abnormalities that might interfere with assessing results. Women may not be pregnant or lactating, and those of child-bearing potential must use a reliable birth control method throughout the trial.

The study is being carried out in accordance with the Declaration of Helsinki and patients may withdraw voluntarily at any stage. Patients are thoroughly informed of the details of the study, have the opportunity to ask questions, and must sign and have witnessed a written informed consent statement before randomization. At each site, the institutional review board or ethical review committee must review and approve the protocol and consent form.

\section{Treatment}

Patients are screened for eligibility at the time of angioplasty or atherectomy, and eligible patients are randomized to quinapril or placebo within 12-72 hours in a double-blind fashion according to a randomization code provided by the sponsor. The 12- to 72-hour win- dow ensures early exposure to quinapril but avoids administering the drug immediately after the procedure during a potentially unstable period. To minimize the chance of first-dose hypotension, patients receive $10 \mathrm{mg}$ of quinapril the first day and a daily dose of $20 \mathrm{mg}$ thereafter. Patients receive either $20 \mathrm{mg}$ of quinapril or placebo once daily for a minimum of 3 years.

Patients are stratified by center as well as by severity of disease, that is, single- vs. multiple-vessel disease. Single-vessel disease is a lesion or lesions with $\geq 50 \%$ luminal diameter narrowing throughout the length of only one of the left anterior descending, left circumflex, or right coronary artery, or in a major branch or branches of one of those vessels. Multiplevessel disease is lesions with $\geq 50 \%$ luminal diameter narrowing in two or more of the major coronary arteries.

Patients are seen at 2-month intervals for the first two visits and then at 4-month intervals for the remainder of the study (Table 1). At their final visit, $30 \%$ of enrolled patients who complete the 3 -year double-blind period will be randomly selected to undergo a repeat coronary angiogram under the same conditions and specifications as the baseline angiogram. If patients require an interim angiogram for whatever reason, every effort will be made to have it conform to the same specifications as the baseline angiogram. Those patients requiring an interim angiogram for a clinical endpoint during months $30-36$ will not undergo a final angiogram at the end of the study, nor will those who require coronary bypass at any point during the study.

The double-blind treatment continues for a minimum of 3 years or until a prespecified number of patients experience at least one cardiac ischemic end-

Table 1. Timetable of clinic visits and procedures

\begin{tabular}{|c|c|c|c|c|c|c|c|c|c|c|c|c|}
\hline $\begin{array}{l}\text { Visit } \\
\text { Study Month }\end{array}$ & $\begin{array}{l}\mathrm{Scr} / \mathrm{D} 1^{b} \\
0\end{array}$ & 0.5 & $\begin{array}{l}\mathrm{D} 2 \\
2\end{array}$ & $\begin{array}{l}\text { D3 } \\
4\end{array}$ & $\begin{array}{l}\mathrm{D} 4 \\
8\end{array}$ & $\begin{array}{l}\text { D5 } \\
12\end{array}$ & $\begin{array}{l}\mathrm{D} 6 \\
16\end{array}$ & $\begin{array}{l}\text { D7 } \\
20\end{array}$ & $\begin{array}{l}\text { D8 } \\
24\end{array}$ & $\begin{array}{l}\text { D9 } \\
28\end{array}$ & $\begin{array}{l}\mathrm{D} 10 \\
32\end{array}$ & $\begin{array}{l}\text { D11 } \\
36\end{array}$ \\
\hline Angiography & $\mathrm{x}$ & & & & & & & & & & & $\mathrm{x}$ \\
\hline Clinic visit & $\mathrm{X}$ & & $\mathrm{X}$ & $\mathrm{x}$ & $\mathrm{x}$ & $\mathrm{x}$ & $\mathrm{x}$ & $\mathrm{X}$ & $\mathrm{X}$ & $\mathrm{x}$ & $\mathrm{x}$ & $\mathrm{x}$ \\
\hline Medical history & $\mathrm{x}$ & & & & & & & & & & & \\
\hline Physical exam & $\mathrm{x}$ & & & & & $\mathrm{x}$ & & & $\mathrm{X}$ & & & $\mathrm{x}$ \\
\hline Patient contact ${ }^{\mathrm{a}}$ & & $\mathrm{X}$ & & & & & & & & & & \\
\hline \multicolumn{13}{|l|}{ Full clinical } \\
\hline laboratory & $\mathrm{x}$ & & $\mathrm{X}$ & $\mathrm{X}$ & $\mathrm{X}$ & $\mathrm{x}$ & & $\mathrm{x}$ & & $\mathrm{x}$ & & $\mathrm{x}$ \\
\hline Lipid measurements & $\mathrm{x}$ & & $\mathrm{X}$ & & & $\mathrm{x}$ & & & & & & $\mathrm{x}$ \\
\hline ECG & $\mathrm{X}$ & & & & & $\mathrm{X}$ & & & & & & $\mathrm{x}$ \\
\hline Medication dispensing & $X^{e}$ & & $\mathrm{X}$ & $\mathrm{x}$ & $\mathrm{x}$ & $\mathrm{x}$ & $\mathrm{x}$ & $\mathrm{x}$ & $\mathrm{x}$ & $\mathrm{x}$ & $\mathrm{x}$ & \\
\hline Reserve samples $^{\mathrm{d}}$ & $\mathrm{X}$ & & & & & $\mathrm{x}$ & & & & & & $\mathrm{x}$ \\
\hline Insulin sensitivitye & $\mathrm{x}$ & & $\mathrm{X}$ & & & & & & & & & $\mathrm{x}$ \\
\hline
\end{tabular}

${ }^{\text {a }}$ Follow-up phone call by coordinator, $2-3$ weeks after randomization.

${ }^{\mathrm{b}}$ Screening and first double-blind visit (D1) may be the same day.

${ }^{c}$ Qualifying patients.

${ }^{\mathrm{d}} \mathrm{Ser}=$ screening visit; $\mathrm{D}=$ double-blind visits.

${ }^{e}$ North American centers only. 
point. Patients who experience nonfatal endpoints will continue to receive quinapril or placebo according to the randomization.

\section{Efficacy parameters}

Cardiac ischemic endpoints. The efficacy evaluations of drug therapy are based primarily on the time to the first cardiac ischemic event, as determined below, during the double-blind period. By agreement with the Cardio-Renal Division of the Food and Drug Administration, cardiac ischemic events are reported as primary study endpoints rather than as adverse events.

An Ischemic Event Endpoint Committee consisting of five physicians involved in the trial reviews all deaths, myocardial infarctions and cases of angina or chest pain requiring hospitalization to decide whether the data support the diagnosis of a clinical ischemic event. For statistical and analytical purposes, ischemic endpoints are defined as follows:

- Sudden cardiac death-death from electrocardiographically (ECG)-proven venricular fibrillation or other fatal arrhythmia with no, or within 1 hour of, cardiac symptomatology; witnessed death within 1 hour of cardiac sympatomatology; unwitnessed death due to acute cardiac insult as confirmed by autopsy

- Death within 28 days of proven myocardial infarction-defined as changes in one or more of three parameters: symptomatology, enzyme elevation, and ECG changes (Table 2)
- Nonfatal myocardial infarction-as defined in Table 2

- Coronary artery bypass grafting (CABG) (Patients with this endpoint can continue the study but will not be considered for the final angiogram.)

- Intervention - such as angioplasty, atherectomy, laser ablation, stenting, or any newly introduced invasive procedure for the management of coronary artery disease.

- Angina requiring hospitalization

Angiography methods. Cardiac catheterization is performed by either the femoral or brachial approach with standard premedication, 5000 units of heparin through the arterial sheath, and nitroglycerin to standardize coronary vasomotor tone. Optimal views with minimum overlap and foreshortening are sought for each of the major coronary artery segments described below. The cine field is carefully centered to include the distal end of the catheter for use as a scaling factor in quantitative analysis.

During the baseline angiogram, the degree of axial (RAO/LAO) rotation and cranial/caudal angulation, and the types, manufacturers, and sizes of catheters for each injection are documented on worksheets. After the patient is discharged from the hospital, catheters, cine film, and a copy of the worksheet are express mailed to the core laboratory.

Angiograms are analyzed as the cine films become available. The referring study center is informed of which angiographic projections from the initial proce-

Table 2. Definite myocardial infarction criteria*

\begin{tabular}{|c|c|c|c|c|c|c|c|c|c|c|}
\hline & & & & & & & & & Cardiac enzymes & \\
\hline & & & & & Electroc & rrdiography & & & $\mathrm{CK}>2 \mathrm{~N}$ & \\
\hline & Symptom & tology & & New & New & New & Other or & & $\mathrm{LDH}>1.5 \mathrm{~N}$ & Other or \\
\hline Category & Typical & Atypical & None & Q wave & inversion & changes & changes & $>5 \%$ & $\&$ SGPT $>3 N$ & changes \\
\hline 1a & $\mathrm{x}$ & & & $<-\cdots$ & h & NY--.--_-.---.-. & $>$ & $\mathrm{X}$ & & \\
\hline $\mathrm{b}$ & $\mathrm{X}$ & & & $\mathrm{X}$ & & & & $<\ldots$ & ANY - & 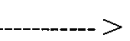 \\
\hline$c$ & $\mathrm{x}$ & & & & $\mathrm{X}$ & & & & $\mathrm{X}$ & \\
\hline$d$ & $\mathrm{X}$ & & & & & $\mathrm{x}$ & & & $\mathrm{X}$ & \\
\hline $2 \mathrm{a}$ & & $\mathrm{X}$ & & $\mathrm{X}$ & & & & $\mathrm{X}$ & & \\
\hline $\mathrm{b}$ & & $\mathrm{x}$ & & $\mathrm{X}$ & & & & & $\mathrm{X}$ & \\
\hline c & & $\mathrm{X}$ & & & $\mathrm{X}$ & & & $\mathrm{X}$ & & \\
\hline $\mathrm{d}$ & & $\mathrm{x}$ & & & $\mathrm{X}$ & & & & $\mathrm{X}$ & \\
\hline $\mathrm{e}$ & & $\mathrm{x}$ & & & & $\mathrm{X}$ & & $\mathrm{X}$ & & \\
\hline $3 \mathrm{a}$ & & & $\mathrm{X}$ & $\mathrm{X}$ & & & & $\mathrm{X}$ & & \\
\hline b & & & $\mathrm{x}$ & & $\mathrm{x}$ & & & & $\mathrm{X}$ & \\
\hline $\mathrm{c}$ & & & $\mathrm{x}$ & $\mathrm{X}$ & & & & & $\mathrm{x}$ & \\
\hline$d$ & & & $\mathrm{x}$ & & $\mathrm{x}$ & & & $\mathrm{x}$ & & \\
\hline
\end{tabular}

* The table is a modification of criteria used in CASS [25].

$\mathrm{CK}=$ creatine kinase; $\mathrm{CK}-\mathrm{MB}=$ creatine kinase $\mathrm{MB}$ isoenzyme; $\mathrm{LDH}=$ lactate dehydrogenase; $\mathrm{LDH}_{1}$ and $\mathrm{LDH}_{2}=$ subfractions; $\mathrm{SGPT}=$ serum glutamic-pyruvic transaminase; $\mathrm{N}=$ normal. 


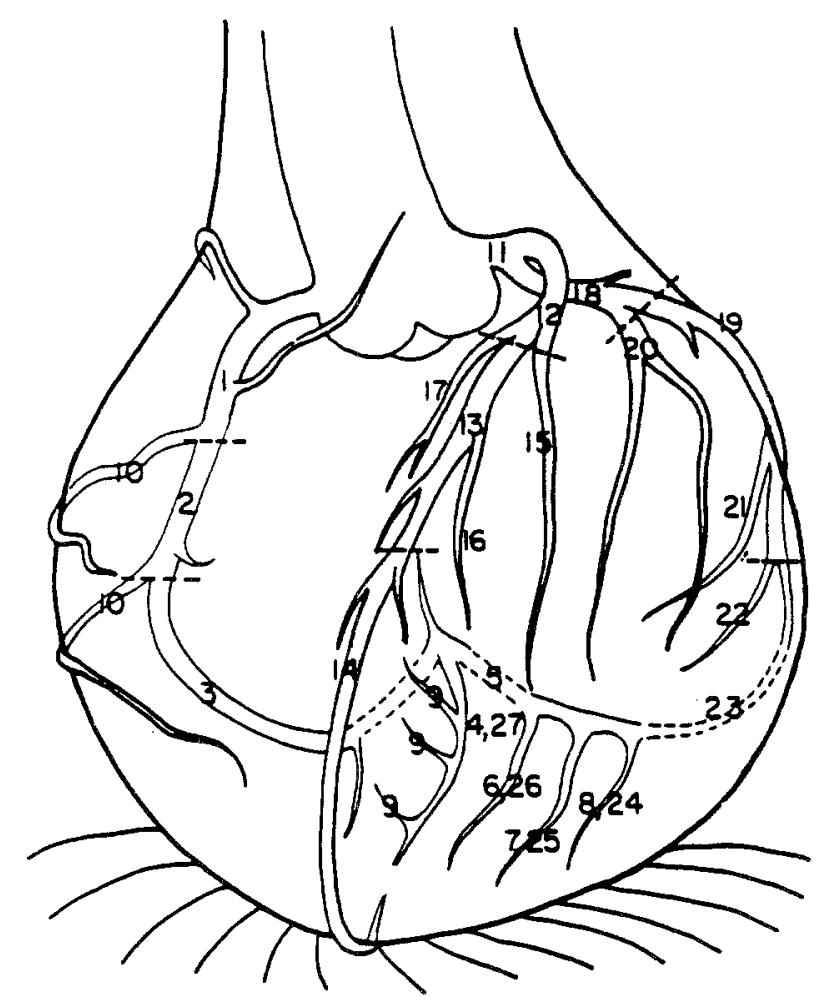

Left main coronary artery (LMCA) - \#11

Left anterior descending artery (LAD) divided as follows:

Prox LAD - proximal segment from division of LM to first diagonal - \#12

Mid LAD - middle segment from first diagonal to second diagonal - \#13

Dist LAD - distal segment distal to second diagonal - \#14

1st diag - first diagonal branch of LAD - \#15

2nd diag - second diagonal branch of LAD - \#16

Left circumflex artery (LCX) divided as follows:

Prox $C X$ - proximal segment from division of $L M$ to first obtuse marginal branch - \#18

Dist $\mathrm{CX}$ - distal segment from the first to the second obtuse marginal branch- \#19

1st OB Marg - first left obtuse marginal branch - \#20

2nd OB Marg - Second left obtuse marginal branch - \#21

1st LPL or RPL - first left or right posterolateral branch - \#24

Right coronary artery ( $\mathrm{RCA}$ ) divided as follows:

Prox RCA - proximal segment from origin to right ventricular branch - \#1

Mid RCA - middle segment from right ventricular branch to acute marginal branch - \#2

Dist RCA - distal segment distal to acute marginal branch - \#3

RPDA - right posterior descending branch - \#4

Fig. 2. Major coronary artery segments from the Coronary Artery Surgery Study [26].

dure are selected for analysis, so they can be duplicated on follow-up. The computerized quantitative coronary analysis system $[23,24]$ has the option of using the cine film digitizers, so the baseline angiogram can be reanalyzed with the follow-up angiogram for optimal evaluation of serial changes. This assures that segments are accurately matched for anatomic landmarks, length, and position in the cardiac cycle. The edge-detection function sums the scaled first and second derivatives, and longitudinal edge detection is performed by a "least cost" method, with the possibility of operator editing. A center line is constructed and the diameter is computed as the distance between the edges perpendicular to the center line. Since catheters of equal outside diameters but of different materials or manufacturers have significantly different radiographically calculated diameters, the analysis program includes a table to calculate a catheterspecific calibration factor [25].

A qualified physician selects and records the views and segments for analysis, choosing the cardiac cycle providing the best opacification and end-diastolic frame for each view. Technicians fully trained to use the quantitative angiographic analysis system perform the analysis.
All evaluable segments $\geq 1.5 \mathrm{~mm}$ diameter and $>5$ $\mathrm{mm}$ length are analyzed (Figure 2) [26]. At least one boundary (proximal or distal) for each segment is related to a precise anatomic landmark, usually a branch origin, and the length of the segment is recorded to aid in precise replication of segments analyzed in follow-up studies. The angiographic analysis from each selected frame is printed out to guide the selection of identical segments for follow-up studies. For all segments, borders of stenotic lesions $>20 \%$ are demarcated, and a normal reference segment is identified when possible. If stenosis is present, the view showing the severest degree of stenosis is selected for analysis.

Because of the normal variability of coronary artery anatomy, the precise demarcation and number of segments analyzed vary from patient to patient. Of the potential segments typically available, evaluation of at least 10 will be attempted (Figure 2 ).

\section{Safety monitoring}

An independent Safety Data Monitoring Committee, comprising three physicians and a statistician not involved in conducting the trial, continuously monitors 


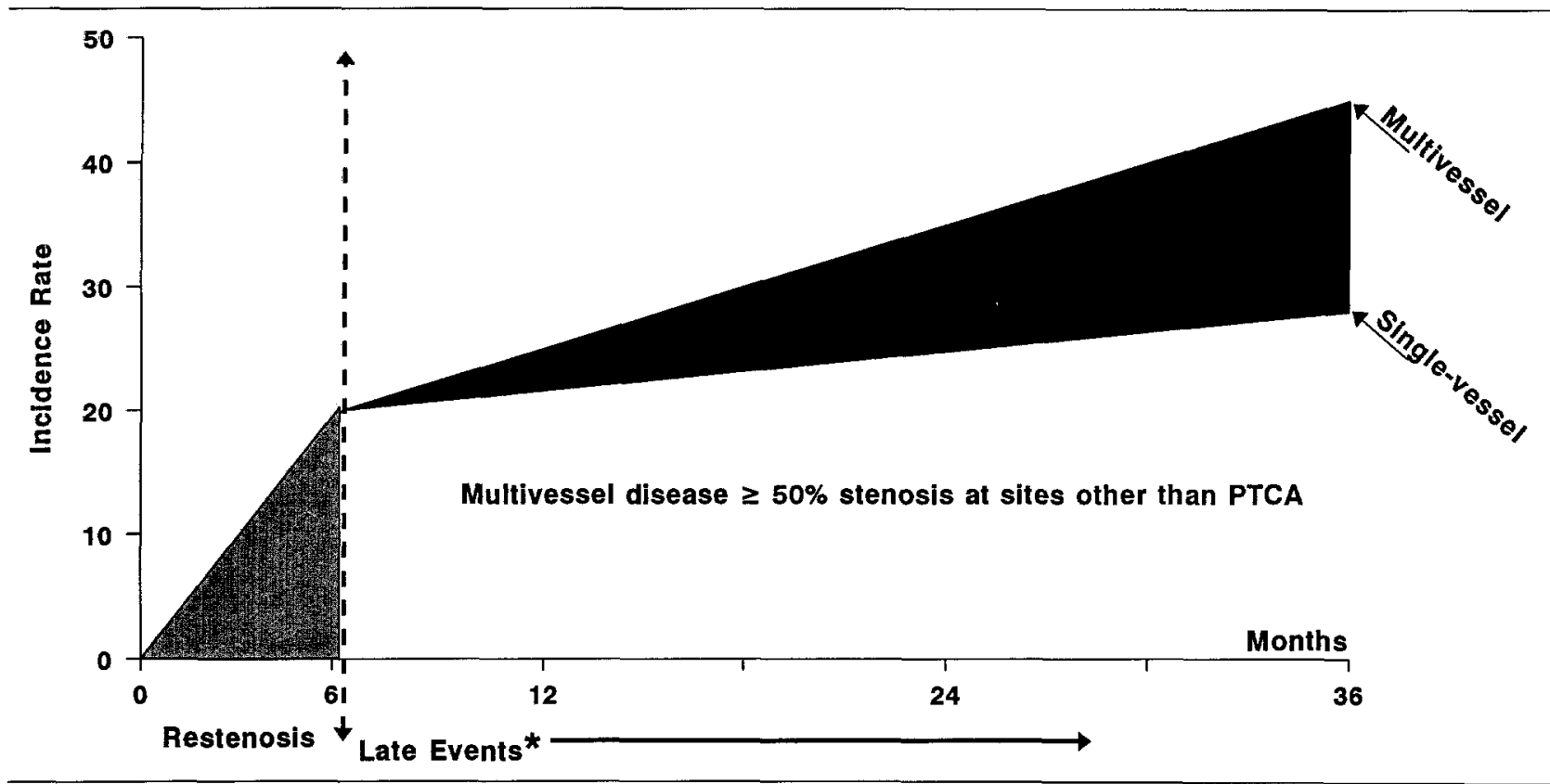

Fig. 3. Anticipated incidence of restenosis [27-31] and late ischemic events [32] for QUIET.* The study population of Weintraub et al. [32] included 9\% diabetics and $40 \%$ hypertensives; mean total cholesterol was $5.97 \mathrm{mmol} / \mathrm{l}$ (231 mg/dl). Ischemic events comprised sudden death, myocardial infarction, coronary artery bypass grafting, and repeat intervention.

all ischemic events and medically serious adverse events. The committee members have sole access to unblinded data and will not communicate any results to the trial sponsor unless they are recommending that the trial be discontinued. The committee meets every 6 months throughout the trial or more frequently if the chairperson deems it necessary.

The committee will inform the sponsor when the placebo group is approaching an overall cardiac ischemic event rate of $36 \%$ and a "late"-events-only rate of $16 \%$ (ischemic events occurring after the first 6 months and not considered to be restenosis) so that these levels would be likely to be reached by the next scheduled committee meeting. After notification, the sponsor will decide whether to stop or continue the trial. This process may be repeated at each subsequent committee meeting. If these event-rate criteria are not reached after 3 years, the committee may recommend continuing the trial for at least 6 additional months. If a formal plan of interim analyses becomes necessary, or if the trial is stopped early due to a safety concern, the Lan-DeMets procedures will be applied [27].

All patients undergo physical examinations at screening and yearly thereafter. Blood pressure and heart rate are recorded at each clinic visit. For patients developing hypotension, medications other than the study drug are adjusted first; if necessary, the dose of quinapril is halved. Any patient with persistent hypotension will be withdrawn from double-blind therapy.
Adverse events will be recorded at each clinic visit or as they are reported to the investigator. Abnormalities in clinical laboratory determinations or ECGs not related to an ischemic endpoint are treated as adverse events.

Patients whose LDL cholesterol level exceeds 5.95 $\mathrm{mmol} / 1(230 \mathrm{mg} / \mathrm{dl})$ on any one determination or remains persistently above $5.17 \mathrm{mmol} / 1(200 \mathrm{mg} / \mathrm{dl})$ on two successive visits despite dietary counselling may receive open-label, lipid-lowering medication and have LDL cholesterol determinations at each visit thereafter. Regardless of therapy, these patients remain in the study for intent-to-treat purposes.

\section{Statistical methods}

Sample size determination. By extrapolation from published data [28-32], we anticipate that $20 \%$ of patients who receive placebo will experience restenosis based on clinical symptomatology within 6 months of the intervention. The assumed rate of cardiac events during months $6-36$ is $8.4 \%$ for patients with singlevessel disease and $24.0 \%$ for those with multiplevessel disease (Figure 3) [31-33]. Because of this wide variation in the expected incidence of cardiac ischemic events during months 6-36 depending on disease severity, the treatment groups are stratified by this parameter to ensure similar proportions in the drug and placebo treatment groups. Given single- and multiplevessel disease in a 50/50 proportion, the expected incidence of cardiac ischemic events during months $6-36$ is $16.2 \%(8.4 \%+24.0 \% \div 2)$. Therefore, we expect 
that $36 \%(20 \%+16 \%)$ of the placebo-treated patients will have at least one cardiac ischemic endpoint, including restenosis, over a 3 -year period. To detect a $25 \%$ reduction of endpoints in the quinapril-treated group (i.e., $27 \%$ of quinapril-treated patients with at least one cardiac ischemic event, including restenosis) with a log-rank test at a two-sided significance level of $5 \%$ with $95 \%$ power requires 750 patients per treatment group.

Sample size and power estimates were also calculated for the two phases of ischemic events likely to be encountered in this trial. To detect a $25 \%$ reduction in incidence of clinical restenosis in the quinapriltreated group within the first 6 months of double-blind treatment using a chi-square test of proportions at a one-sided 5\% significance level, 1700 patients will provide approximately $80 \%$ power. To detect a $25 \%$ reduction in ischemic events during months 6-36 in the quinapril-treated group with a log-rank test at a two-sided significance level of 5\%, 1700 patients will provide $>80 \%$ power.

For the angiographic analyses the incidence of progression in the placebo treatment group was assumed to be 0.45 ( $45 \%$ of patients in the placebo treatment group demonstrating "progression"-however defined-over a 3 -year period) [3,4,7,8,34-40]. Thus, for a test with $80 \%$ power at a two-sided $5 \%$ significance level to detect a $30 \%$ reduction (to 0.315 ) in the quinapril treatment group, 203 patients are required per treatment group. Assuming a $15 \%$ dropout rate, 240 patients per treatment group are needed.

Efficacy analyses. The time to the first cardiac ischemic event will be analyzed by a two-sided log-rank test with a $5 \%$ level of significance. Logistic regression and Cox Proportional Hazards models will be used to determine the relative risk (odds ratio and hazard ratio) of cardiac ischemic events in the treatment groups and the 95\% confidence interval for the odds ratio and hazard ratio, as well as to assess relationships between various risk factors, as determined before breaking the blind, and both outcome and time to event.

The primary analysis will be based on the intent-totreat population to include all patients randomized to treatment whether or not they are active in the trial at the time of any cardiac ischemic event. Analyses will be done across all study centers, continents, and randomization strata, without interaction terms. Supplemental analyses will consider both the severity of individual endpoints and the possibility of multiple endpoints. Survival analysis will be done on the time to the most serious event rather than the first event. This ranks severity of endpoints as follows in ascending order of severity: angina requiring hospitalization, invasive intervention, $\mathrm{CABG}$, nonfatal myocardial infarction, fatal myocardial infarction, and sudden cardiac death.
Further analyses will focus on specific endpoints, individually and together, such as myocardial infarction and subsequent sudden death. Such a grouping of endpoints will allow easier analysis of the data within a competing risks framework. The effects of treatment on specific endpoints and the relationship among them will be examined.

The interaction of treatment group with the stratification variables will be analyzed at the $5 \%$ signifcance level. If any interaction is significant, singlefactor, pairwise comparisons will be done at the $5 \%$ significance level, two-tailed.

The incidence of early events within the first 6 months and cardiac ischemic events between months 6 and 36 will be analyzed as above, using survival analysis methods.

Similar analyses will be done for an evaluable patient population, defined as those who satisfy criteria for compliance to study medication and adherence to major inclusion/exclusion criteria (per protocol population). Evaluability will be determined prior to breaking the blind.

Angiographic analyses. The angiographic progression of coronary atherosclerosis will be determined from changes in four measurements:

- minimum lumen diameter

- percent stenosis

- mean segment diameter

- appearance of new lesions

For each patient, the mean of each of these measurements for all evaluable segments will be calculated to provide indices of change from the baseline. At present, the mean segment diameter index (MSDI) is considered to be the most appropriate efficacy parameter for statistical analysis of angiographic results.

Because the likely extent of MSDI change in 3 years is unknown, "progression" has been defined on the basis of empirical rules, applying the following procedures to blinded clinical data. Without breaking the blind, the following three items will be performed as necessary:

1. The median change from baseline in MSDI will be computed based on all patients completing the 3year, double-blind treatment period, regardless of treatment group. This median will be used to construct two categorical groups-one consisting of patients with disease severity $>$ median and the other of patients with disease severity $\leq$ median.

2. During the study period, continuing research may identify a more sensitive parameter that indicates changes in coronary artery atherosclerosis caused by various treatments. If possible, the computation 
described above will be performed on this newly designated parameter.

3. When the most sensitive measure of treatment change is identified, the construction of the categorical groups may be adjusted in order to further define disease "progression." This definition will be used to classify a patient as a progressor (disease severity $>$ median) or nonprogressor (disease severity $\leq$ median).

Secondary angiographic parameters will include measures derived from baseline and final angiograms for each patient. Mean values for the angiographic change in each treatment group will be compared, generally by analysis of variance (ANOVA), including the center and disease severity stratification indicator in the model as covariates. If statistical considerations warrant, appropriate alternatives to ANOVA (nonparametric methods) will be applied. Other covariates, specified before breaking the blind, will be considered in exploratory analyses. Secondarily, the percentage of patients experiencing specified types of changes will be explored, for example, the percentage with disease progression by treatment group, with center and stratification factor as blocking factors. Percentages between groups will be compared by logistic regression with center and stratification as blocking factors.

\section{Discussion}

In designing any major intervention study, one of the challenges is to define an appropriate study population. Too narrow a population may be difficult to recruit and, ultimately, may produce findings not clearly applicable to the clinical situation, while too broad a population may introduce confounding variables and hinder interpretation of results. QUIET targets a homogeneous population with coronary artery disease, defined as patients undergoing angioplasty or atherectomy, common interventions with reported similarities in restenosis rates [41]. It should be recognized that the study is not primarily a restenosis trial; restenosis is, however, one of several endpoints.

The selection of normotensive patients, including those with hypertension controlled at baseline, permits a placebo control, reducing the likelihood of concluding that any beneficial effect of drug may relate primarily to blood pressure reduction, as suggested by Waters et al. in their study of nicardipine [8], and demonstrates that benefit can be extended to normotensive patients (SBP $\geq 100 \leq 160 \mathrm{mmHg}$; DBP $\leq 95$ $\mathrm{mmHg}$ ) even if blood pressure reductions are apparent. A similar rationale accounts for the requirement of normal LDL cholesterol levels [ $\leq 4.27 \mathrm{mmol} / 1(165$ $\mathrm{mg} / \mathrm{dl})$ ], since concomitant modification of this risk factor could ultimately confound a positive result. By allowing non-insulin-dependent diabetics to participate in the study, we have the opportunity to evaluate the benefit of an ACE inhibitor in a population at increased risk of cardiovascular disease and perhaps gain insight into the role of insulin resistance in the progression of coronary artery disease.

Studies with angiographic endpoints $[2-4,7,8]$ have shown that medical therapy can attenuate the rate of lesion development and/or reduce existing lesions. However, most angiographic studies have had too small a sample size to detect a reduction in morbidity or mortality associated with the measured changes in coronary artery diameter. The relatively large sample in QUIET accommodates both clinical and angiographic endpoints in defining efficacy.

While not the first study to look at a spectrum of clinical sequelae, QUIET identifies varied endpoints as primary efficacy parameters, constructs a severity scale that recognizes multiple endpoints within one patient in the "time to event" analysis, and allows for different temporal sequences of events during the double-blind phase ("early" vs. "late" events). Since "early" events related to restenosis may represent different pathophysiological processes than "late" events, such as atherosclerosis, plaque rupture, and thrombosis, it was necessary to power (albeit at $80 \%$ ) the study for both phases.

In summary, QUIET is the first study to address the long-term effects of ACE inhibition on the natural history of coronary artery disease in a normolipidemic population without left ventricular dysfunction, both in terms of clinical endpoints and angiographically. In addition to insulin resistance, other substudies will examine endothelial reactivity and intracoronary ultrasound evidence of plaque volume and restenosis. Enrollment in QUIET is complete and the trial is expected to conclude by the end of January 1996. Evidence of reduction in the ischemic event rate could have important implications for the use of quinapril in both the secondary, and possibly the primary, prevention of cardiac disease.

\section{Acknowledgments}

The authors express their appreciation to Susan J. Berman, MA, for editorial guidance, Harry Haber, MPH, for designing the statistical analyses, and David Canter, MD, For significant contributions toward the final protocol. The research was supported by Parke-Davis Pharmaceutical Research, Division of WarnerLambert Company, Inc., Ann Arbor, Michigan.

\section{References}

1. Ornish D, Brown SE, Scherwitz LW, et al. Can lifestyle changes reverse coronary heart disease? Lancet 1990;336: 129-133. 
2. Blankenhorn DH, Brooks SH. Angiographic trials of lipidlowering therapy. Arteriosclerosis 1981;1:242-249

3. Blankenhorn DH, Johnson RL, Nessim SA, et al. and the CLAS Investigators and Staff. The Cholesterol Lowering Atherosclerosis Study (CLAS): Design, methods, and baseline results. Controlled Clin Trial 1987;8:354-387.

4. Brown G, Albers JJ, Fisher LD, et al. Regression of coronary artery disease as a result of intensive lipid-lowering therapy in men with high levels of apolipoprotein B. $N E n g l$ $J$ Med 1990;323:1289-1298.

5. Buchwald H, Moore RB, Varco RL. Surgical treatment of hyperlipidemia. Circulation 1974;49(Suppl 1):I1-I37.

6. Buchwald H, Varco RL, Matts JP, et al. and the POSCH Group. Effect of partial ileal bypass surgery on mortality and morbidity from coronary heart disease in patients with hypercholesterolemia. $N$ Engl J Med 1990;323:946-955.

7. Lichtlen PR, Hugenholtz PG, Rafflenbeul W, et al. Retardation of angiographic progression of coronary artery disease by nifedipine. Lancet 1990;335:1109-1113.

8. Waters D, Lesperance J, Francetich M, et al. A controlled clinical trial to assess the effect of a calcium channel blocker upon progression of coronary atherosclerosis. Circulation 1990;82:1940-1954.

9. Foris G, Dezso B, Medgyesi GA, Fust G. Effect of angioten$\sin$ II on macrophage functions. Immunology 1983;48: $529-535$.

10. Chobanian A, Haudenschild C, Nickerson C, Drago R. Antiatherogenic effect of captopril in the Watanabe heritable hyperlipidemic rabbit. Hypertension 1990;15:327-331.

11. Chobanian AV. 1989 Corcoran Lecture: Adaptive and maladaptive response of the arterial wall to hypertension. $\mathrm{Hy}$ pertension 1990; 15:666-674.

12. Vanhoutte PM, Auch-Schwelk W, Biondi ML, et al. Why are converting enzyme inhibitors vasodilators? $\mathrm{Br} J \mathrm{Clin}$ Pharmacol 1989;28:95S-104S.

13. Powell JS, Clozel J-P, Muller RKM, et al. Inhibitors of angiotensin-converting enzyme prevent myointimal proliferation after vascular injury. Science 1989;245:186-188.

14. Aberg G, Ferrer P. Effects of captopril on atherosclerosis in cynomolgus monkeys. J Cardiovasc Pharmacol 1990; 15(Suppl 5):S65-S72.

15. The Multicenter European Research Trial With Cilazapril After Angioplasty to Prevent Transluminal Coronary Obstruction and Restenosis (MERCATOR) Study Group. Does the new angiotensin converting enzyme inhibitor cilazapril prevent restenosis after percutaneous transluminal coronary angioplasty? Circulation 1992;86:100-110.

16. The Multicenter European Research Trial With Cilazapril After Angioplasty to Prevent Transluminal Coronary $\mathrm{Ob}-$ struction and Restenosis (MERCATOR) Study Group. Presented at XVth Congress of the European College of Cardiology, September, 1991; Amsterdam, The Netherlands.

17. The SOLVD Investigators. Effect of enalapril on survival in patients with reduced left ventricular ejection fractions and congestive heart failure. $N$ Engl $J$ Med 1991;325:293-302.

18. Yusuf S, pepine C, Garces C, et al. Effect of enalapril on myocardial infarction and unstable angina in patients with low election fraction. Lancet 1992;340:1172-1178.

19. Pfeffer M, Braunwald E, Moye L, et al. Effect of captopril on mortality and morbidity in patients with left ventricular dysfunction after myocardial infarction. $N \mathrm{Engl} \mathrm{J} \mathrm{Med}$ 1992;327:669-677
20. Dzau VJ. Short- and long-term determinants of cardiovascular function and therapy: contributions of circulating and tissue renin-angiotensin systems. J Cardiovase Pharmacol 1989;14(Suppl 4):S1-S5.

21. Fabris B, Yamada H, Cubela $R$, et al. Characterization of cardiac angiotensin converting enzyme ( $\mathrm{ACE}$ ) and in vivo inhibition following oral quinapril to rats. $B r J$ Pharmacol 1990;100:652-655.

22. Johnston CI, Mendelsohn FAO, Cubela RB, et al. Inhibition of angiotensin converting enzyme (ACE) in plasma and tissues: studies ex vivo after administration in ACE inhibitors. $J$ Hypertens 1988;6(Suppl 3):S17-S22.

23. Alderman E1, Berte LE, Harrison DC, Sanders W. Quantitation of coronary dimensions using digital image processing. Proceedings of SPIE-The International Society for Optical Engineering. Palo Alto, CA: Stanford University, 1981, pp 273-278.

24. Leung WH, Sanders W, Alderman EL. A coronary artery quantitation and data management system for paired cineangiograms. Cathet Cardiovase Diagn 1991;24:121-134.

25. Leung WH, Demopulos PA, Alderman El, Sanders W, Stadius ML. Evaluation of catheters and metallic catheter markers as calibration standard for measurement of coronary dimension. Cathet Cardiovasc Diagn 1990;21:148-153.

26. National Heart, Lung, and Blood Institute Coronary Artery Surgery Study. A multicenter comparison of the effects of randomized medical and surgical treatment of mildly symptomatic patients with coronary artery disease, and a registry of consecutive patients undergoing coronary angiography. Circulation 1981;63(6, Part 2):I1-I81.

27. Lan KKG, Demets DL. Discrete sequential boundaries for clinical trials. Biometrika 1983;70:659-663.

28. Faxon DP, Ruocco N, Jacobs AK. Long term outcome of patients after percutaneous transluminal coronary angioplasty. Circulation 1990;81(Suppl IV):IV9-IV13.

29. Ellis S, Cowley M, DiSciascio G, et al. Determinants of 2-year outcome after coronary angioplasty in patients with multivessel disease on the basis of comprehensive preprocedural evaluation. Implication for patient selection. Circulation 1991;83:1905-1914.

30. Gruentzig AR, King SB, Schlumph M, Siengenthaler W. Long-term follow up after percutaneous transluminal coronary angioplasty. The early Zurich experience. $N$ Engl J Med 1987;316:1127-1132.

31. Detre K, Holubkov R, Kelsey S, et al. and coinvestigators of the National Heart, Lung, and Blood Institute's Percutaneous Transluminal Coronary Angioplasty Registry. Circulation 1989;80:421-428.

32. Talley JD, Hurst JW, King SB, et al. Clinical outeome 5 years after attempted pereutaneous transluminal coronary angioplasty in 427 patients. Circulation 1988;77:820-829.

33. Weintraub WS, Ghazzal ZMB, Cohen CL, et al. Clinical implications of late proven patency after successful coronary angioplasty. Circulation 1991;84:572-582.

34. Arntzenius AC, Kromhout D, Barth JD, et al. Diet, lipoproteins, and the progression of coronary atherosclerosis. The Leiden Intervention Trial. N Engl J Med 1985;312:805811.

35. Blankenhorn DH, Nessim SA, Johnson RL, et al. Beneficial effects of combined colestipol-niacin therapy on coronary atherosclerosis and coronary venous bypass grafts. JAMA 1987;257:3233-3240.

36. Blankenhorn DH, Alaupovic P, Wickham E, et al. Predic- 
tion of angiographic change in naive human arteries and aortocoronary bypass grafts. Circulation 1990;81:470476.

37. Cohn K, Sakai FJ, Langston MF. Effect of clofibrate on progression of coronary disease. A prospective angiographic study in man. Am Heart $J$ 1975;89:591-598.

38. Frick MH, Valle M, Harjola P-T. Progression of coronary artery disease in randomized medical and surgical patients over a 5-year angiographic follow-up. Am $J$ Cardiol 1983; 52:681-685.

39. Levy RI, Brensike JF, Epstein SE, et al. The influence of changes in lipid values induced by cholestyramine and diet on progression of coronary artery disease: results of NHLBI Type II Coronary Intervention Study. Circulation 1984; 69:325-337.

40. Waters D, Freedman D, Lesperance J, et al. Design features of a controlled clinical trial to assess the effect of a calcium entry blocker upon the progression of coronary artery disease. Controlled Clin Trials 1987;8:216-242.

41. Garratt KN, Holmes DR, Bell MR, et al. Restenosis after directional coronary atherectomy: differences between primary atheromatous and restenosis lesions and influence of subintimal tissue resection. $J$ Am Coll Cardiol 1990;16: $1665-1675$ 